\title{
The hidden chemolithoautotrophic metabolism of Geobacter sulfurreducens uncovered by adaptation to formate
}

\author{
Tian Zhang ${ }^{1,2,3} \cdot$ Xiao-Chen Shi ${ }^{1,2,3} \cdot$ Ran Ding ${ }^{1,3} \cdot K^{2} X^{4} \cdot$ Pier-Luc Tremblay ${ }^{1,3}$
}

Received: 29 August 2019 / Revised: 24 April 2020 / Accepted: 29 April 2020 / Published online: 12 May 2020

(c) The Author(s), under exclusive licence to International Society for Microbial Ecology 2020

\begin{abstract}
Multiple Fe(III)-reducing Geobacter species including the model Geobacter sulfurreducens are thought to be incapable of carbon dioxide fixation. The discovery of the reversed oxidative tricarboxylic acid cycle (roTCA) for $\mathrm{CO}_{2}$ reduction with citrate synthase as key enzyme raises the possibility that $G$. sulfurreducens harbors the metabolic potential for chemolithoautotrophic growth. We investigate this hypothesis by transferring G. sulfurreducens PCA serially with Fe(III) as electron acceptor and formate as electron donor and carbon source. The evolved strain T17-3 grew chemolithoautotrophically with a 2.7 -fold population increase over $48 \mathrm{~h}$ and a Fe(III) reduction rate of $417.5 \mu \mathrm{M} \mathrm{h}^{-1}$. T17-3 also grew with $\mathrm{CO}_{2}$ as carbon source. Mutations in T17-3 and enzymatic assays point to an adaptation process where the succinyl-CoA synthetase, which is inactive in the wild-type, became active to complete the roTCA cycle. Deletion of the genes coding for the succinyl-CoA synthetase in T17-3 prevented growth with formate as substrate. Enzymatic assays also showed that the citrate synthase can perform the necessary cleavage of citrate for the functional roTCA cycle. These results demonstrate that G. sulfurreducens after adaptation reduced $\mathrm{CO}_{2}$ via the roTCA cycle. This previously hidden metabolism can be harnessed for biotechnological applications and suggests hidden ecological functions for Geobacter.
\end{abstract}

\section{Introduction}

Biological $\mathrm{CO}_{2}$ reduction is an essential reaction for life on Earth responsible for the synthesis of most organic carbon molecules. Until recently, six $\mathrm{CO}_{2}$ fixation metabolic

These authors contributed equally: Tian Zhang, Xiao-Chen Shi

Supplementary information The online version of this article (https:// doi.org/10.1038/s41396-020-0673-8) contains supplementary material, which is available to authorized users.

$\triangle$ Tian Zhang

tzhang@whut.edu.cn

$\triangle$ Pier-Luc Tremblay pierluct@whut.edu.cn

1 State Key Laboratory of Silicate Materials for Architectures, Wuhan University of Technology, Wuhan 430070, PR China

2 School of Materials Science and Engineering, Wuhan University of Technology, Wuhan 430070, PR China

3 School of Chemistry, Chemical Engineering and Life Science, Wuhan University of Technology, Wuhan 430070, PR China

4 Center for Material Research and Analysis, Wuhan University of Technology, Wuhan 430070, PR China pathways were known $[1,2]$. One of these pathways is the reductive tricarboxylic acid cycle (rTCA), which shares multiple enzymatic reactions with the oxidative TCA cycle (oTCA) of anaerobic microorganisms, but operating in reverse for $\mathrm{CO}_{2}$ reduction [3-6]. The oTCA cycle is a common metabolic pathway performing the oxidation of acetyl-CoA for the generation of energy and redox equivalents. The only key enzyme of the oTCA cycle that is not involved in the rTCA cycle is the citrate synthase (CS), which catalyzes the condensation of acetyl-CoA and oxaloacetate into citrate. In the rTCA cycle, citrate is converted into acetyl-CoA and oxaloacetate by an ATP-dependent citrate lyase (ACL) or by an ATP-dependent two-step pathway catalyzed by a citryl-CoA synthetase and a citrylCoA lyase (CCS/CCL) [7-11].

Until recently, the CS reaction was regarded as irreversible under physiological conditions [1, 12-14]. Two studies have demonstrated that it is not always the case and that the oTCA cycle can operate in reverse with CS instead of ACL or CCS/CCL as key enzyme for $\mathrm{CO}_{2}$ reduction in the hydrogen or acetate-oxidizing and sulfur-reducing deltaproteobacterium Desulfurella acetivorans and hydrogenoxidizing and sulfur-reducing Aquificae bacterium Thermosulfidibacter takaii [15, 16]. This carbon fixation 
pathway has been named reversed oxidative TCA cycle (roTCA) since it involves the same series of enzymes as the oTCA cycle but operating the opposite direction. Based on this new discovery and due to the widespread presence of the oTCA cycle in microbial community, it is likely that the capacity of chemolithotrophic inorganic carbon fixation in many microbes cannot be investigated only with genome annotation [17]. Likewise, microbial species with oTCA cycle isolated via laboratory cultivation with organic carbon substrates may have a hidden capability of inorganic carbon fixation encoded in their genomes, which could be revealed if put under the right selection pressure.

$\mathrm{Fe}(\mathrm{III})$-reducing anaerobic Geobacter species are major contributor to the carbon and mineral cycles in iron-rich habitats including soils, aquatic sediment, and subsurface environments where they are often found as the dominant population $[18,19]$. Because of their capacity to couple acetate oxidation via the oTCA cycle with $\mathrm{Fe}$ (III) reduction, one of the main ecological functions of Geobacter spp. is the degradation of organic acids generated by fermentative microbes [20-22]. Besides Fe(III)-based acceptors, Geobacter spp. can also transfer electrons directly to methanogens for methane production in diverse environments such as wetlands and anaerobic digesters [23-25]. Another widely investigated attribute of Geobacter spp. is their capacity to either transfer electrons to an electrode for the production of electricity in microbial fuel cell or to use an electrode as electron donor [26-28]. The most commonly studied Geobacter is Geobacter sulfurreducens PCA because it is the first one to be sequenced in the genus and gene recombination is easy to be applied [29, 30]. G. sulfurreducens was isolated as an obligately heterotroph with acetate as an electron donor and carbon source [31]. On the other hand, the functional rTCA cycle in G. sulfurreducens was developed with expressing ACL from Chlorobium limicola [26].

Besides genetic engineering, the metabolism and cell functions of $G$. sulfurreducens have been investigated and modified via adaptive laboratory evolution (ALE). ALE can serve to study cell metabolism and response to stresses as well as to develop more efficient and robust industrial strains [32-36]. During ALE, a microbe is cultivated under a selective pressure over many generations, which can lead to the acquisition of mutations conferring or altering metabolic capacities [37-39]. For G. sulfurreducens, ALE has been used to investigate and improve extracellular electron transfer to insoluble electron acceptor as well as the metabolic pathway involved in the oxidation of the organic substrate lactate [40-42].

Here, G. sulfurreducens PCA wild-type was serially transferred into a chemolithoautotrophic growth medium with formate as electron donor and carbon source and $\mathrm{Fe}$ (III) as electron acceptor ( $\mathrm{FcF})$. The capability of chemolithoautotrophic growth of the FcF-evolved strain was further evaluated in a medium, where $\mathrm{H}_{2}$ was the electron donor, $\mathrm{CO}_{2}$ was the carbon source, and $\mathrm{Fe}(\mathrm{III})$ was the electron acceptor. Genome of FcF-evolved clones was sequenced to identify the mutations that may be responsible for the observed metabolic changes. Enzymatic assays, quantitative PCR, functional genetic, and isotopologue analysis of proteinogenic amino acids were employed to investigate the carbon fixation pathway responsible for chemolithoautotrophic growth.

\section{Materials and methods}

\section{Strain and growth condition}

Strains used in this study are listed in Table S1. G. sulfurreducens PCA was routinely cultured in $25 \mathrm{ml}$ anaerobic pressure tubes (15 ml headspace) with a $\mathrm{N}_{2}: \mathrm{CO}_{2}(80: 20 ; 1$ atm) atmosphere at $30{ }^{\circ} \mathrm{C}$ in either acetate-fumarate (NBAF) or acetate-Fe(III) citrate medium (FcA) at $\mathrm{pH} 6.8$ as described previously [29, 31]. Formate-adapted strains were routinely maintained in $\mathrm{FcF}$ medium, which has the same composition as $\mathrm{FcA}$ but with formate replacing acetate. Heterotrophic growth experiments were conducted with $\mathrm{NBAF}$ (acetate $10 \mathrm{mM}$, fumarate $40 \mathrm{mM}$ ) and FcA (acetate $10 \mathrm{mM}, \mathrm{Fe}(\mathrm{III})$ citrate $50 \mathrm{mM}$ ) media. Chemolithoautotrophic growth experiments were carried out with $\mathrm{FcF}$ (formate $40 \mathrm{mM}, \mathrm{Fe}(\mathrm{III})$ citrate $50 \mathrm{mM}$ ) and $\mathrm{FnF}$ (formate $20 \mathrm{mM}, \mathrm{Fe}(\mathrm{III})$-NTA $10 \mathrm{mM}$ ) media. FnF medium has the same composition as FcF but with Fe(III)-NTA instead of $\mathrm{Fe}$ (III) citrate as electron acceptor. Chemolithoautotrophic growth was also assessed in $\mathrm{FcHC}$ medium, which is similar to FcF but without formate, and the $\mathrm{N}_{2}: \mathrm{CO}_{2}$ atmosphere replaced by $\mathrm{H}_{2}: \mathrm{CO}_{2}(80: 20 ; 1.3 \mathrm{~atm})$. Additional growth experiments were conducted with an inorganic carbon-free $\mathrm{FcH}$ medium $\left(\mathrm{H}_{2}-\mathrm{Fe}\right.$ (III) citrate $50 \mathrm{mM}$ ), where the $\mathrm{CO}_{2} / \mathrm{HCO}_{3}{ }^{-}$buffer system was replaced by $20 \mathrm{mM}$ MOPS pH 7.0 buffer in the presence or not of $1 \mathrm{mM}$ acetate. In FHC medium, the atmosphere is pure $\mathrm{H}_{2}(1.3 \mathrm{~atm})$. The concentration of $\mathrm{Fe}(\mathrm{II})$ in $\mathrm{Fe}$ (III)-reducing cultures was measured with the ferrozine assay [43].

\section{Adaptive laboratory evolution with formate}

The ALE experiment with formate as electron donor and carbon source was started by transferring $15 \%$ of an FcAgrown G. sulfurreducens PCA culture into $10 \mathrm{ml}$ sterile $\mathrm{FcF}$ medium. Subsequent $15 \%$ transfers were done each time when $\mathrm{FcF}$ cultures grown anaerobically at $30{ }^{\circ} \mathrm{C}$ reached 15 $\mathrm{mM} \mathrm{Fe}(\mathrm{II})$. The ALE experiment was stopped after 23 transfers as $\mathrm{Fe}$ (III) reduction rate stabilized and did not accelerate further. Culture from transfer \#17, which was the 
Fig. 1 The TCA cycle of $G$. sulfurreducens in both directions. a roTCA cycle for carbon fixation. All the enzymes required for roTCA cycle are present in G. sulfurreducens. Genes coding for ACL or CCS/ CCL required for carbon fixation rTCA cycle are not found in $G$. sulfurreducens. b oTCA cycle for organic substrate oxidation. When growing with acetate as substrate, G. sulfurreducens has a modified oTCA cycle where succinyl-CoA synthetase has minimal activity and is mostly replaced by the succinyl-CoA: acetate CoA-transferase [21, 54].
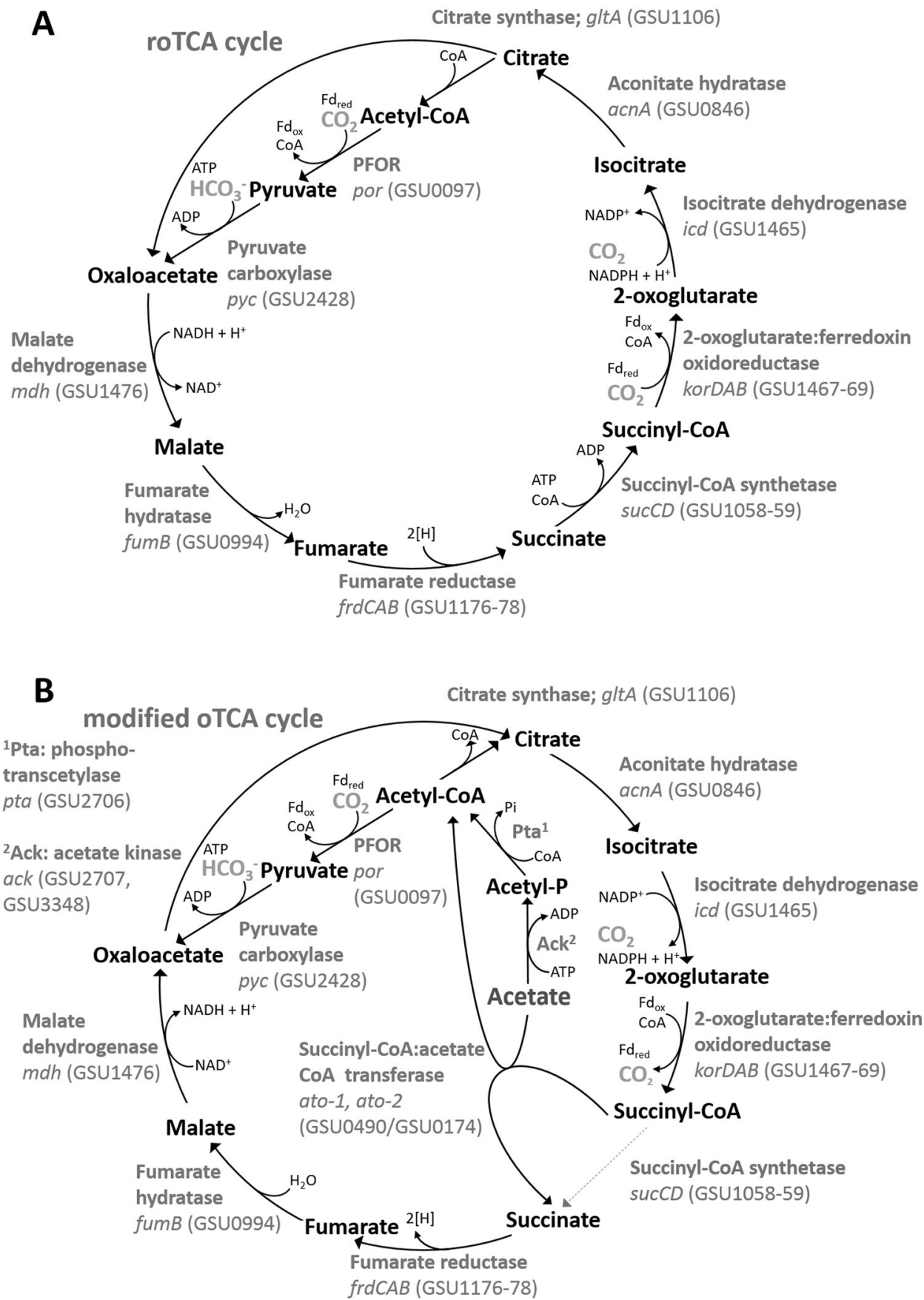

fastest to reach $15 \mathrm{mM} \mathrm{Fe}(\mathrm{II})$, was streaked on plates and several colonies were picked for cultivation into $\mathrm{FcF}$ liquid medium. PCR was used to confirm that the isolated clones were G. sulfurreducens.

\section{Whole-genome DNA sequencing}

Genomic DNA of formate-adapted clones T17-3 and T174 was extracted with the M5 Bacteria Genomic DNA Kit
(Mei5 Biotechnology, China). The NEB Next Ultra DNA Library Prep Kit for Illumina (NEB, MA, USA) was used to generate genomic DNA libraries. Adapters were ligated to DNA fragments ranging from 300 to $400 \mathrm{bp}$, which were then recovered by beads purification. A PCR of 12 cycles was used to enrich the adapter-modified DNA before high-throughput sequencing with an Illumina HiSeq 4000 (Illumina, CA, USA) with a paired-end protocol and read lengths of $150 \mathrm{nt}$. The sequencing reads 
were trimmed with PRINSEQ and aligned for variant calling with the Picard DNA-seq analysis pipeline and BBTools [44-46]. The reference genome for the analysis was $G$. sulfurreducens PCA (NCBI reference sequence NC_002939.5). All the samples have an average coverage of at least $30 \times$.

\section{Quantitative reverse transcription PCR (RT-qPCR)}

Sequences of all primers used for RT-qPCR are listed in Table S2. Total RNA was extracted with the TRIzol Max Bacterial RNA Isolation Kit (Thermo Fisher Scientific, MA, USA) from mid-log FcF or FcA cultures. RNA samples were then treated with DNase I (RNase-free) (Thermo Fisher Scientific) to remove DNA contamination. cDNA was generated from treated RNA samples with the RevertAid First Strand cDNA Synthesis Kit (Thermo Fisher Scientific). The SYBR green Real-Time PCR supermix (Mei5 Biotechnology) and the CFX Connect Real-Time PCR Detection System (Bio-Rad, CA, USA) were used to amplify and quantify PCR products for GSU0514, sucC, and gltA. The expression of these three genes was normalized with proC expression, a gene expressed constitutively in G. sulfurreducens [47]. Relative levels of expression of GSU0514, sucC, and gltA were calculated by the $2^{-\Delta \Delta C T}$ method [48].

\section{sucCD ${ }^{-}$mutant construction}

Sequences of all primers used for construction of $\Delta$ sucCD:: $\mathrm{Km}^{\mathrm{r}}$ mutant allele are listed in Table S2. The mutant construction was done as previously described [49]. The coding sequence of sucCD was replaced by a kanamycin resistance cassette. Primer pair sucCDUP/ sucCDfusUP was used to amplify 508 bp upstream from sucC (GSU1058) and sucCDfusDN/sucCDDN $582 \mathrm{bp}$ downstream from sucD (GSU1059) with G. sulfurreducens T17-3 genomic DNA as template. The KmRXhoIUp/ KmRXbaIDn primer pair was used to amplify the kanamycin resistance cassette from pBBR1MCS-2 [50]. UP and DN PCR products were combined by overlapping extension PCR resulting into the $\triangle$ sucCD allele, and then cloned with a Zero Blunt TOPO PCR Cloning Kit (Thermo Fisher Scientific). The kanamycin resistance cassette was digested by XhoI-XbaI and ligated with the T4 DNA ligase into the $\triangle \operatorname{suc} C D$ allele resulting into a $\Delta$ suc $C D:: \mathrm{Km}^{\mathrm{r}}$ allele. The vector carrying $\Delta s u c C D:: \mathrm{Km}^{\mathrm{r}}$ was linearized by digesting with $\mathrm{ClaI}$ and concentrated by ethanol precipitation [40]. Electroporation into the adapted strain T17-3 of the linearized vector carrying $\Delta$ sucCD:: $\mathrm{Km}^{\mathrm{r}}$ and mutant selection was performed as previously described $[29,51]$. The suc $C D^{-}$mutant was verified by PCR and Sanger sequencing.

\section{Cell counting, high performance liquid chromatography, isotopologue analysis, and enzymatic assays}

The methods for cell counting, high performance liquid chromatography, isotopologue analysis, succinyl-CoA synthetase, and CS assays have been included in the Supplementary Information.

\section{Results}

\section{Adaptation of $G$. sulfurreducens with formate as electron donor and carbon source}

It has been assumed that G. sulfurreducens PCA has a heterotrophic metabolism and cannot grow with $\mathrm{CO}_{2}$ or other $\mathrm{C} 1$ compounds such as formate as sole source of carbon. In previous studies investigating the metabolism of G. sulfurreducens with $\mathrm{H}_{2}, \mathrm{CO}$, or formate as electron donor, acetate and/or fumarate were always provided as carbon sources [52, 53]. The genome sequence of G. sulfurreducens also supported the claim that this bacterium is possibly an obligate heterotroph since genes coding for the essential enzymes of the six previously known carbon fixation pathways are absent (Table S3) [30].

With the recent discovery of the CS-dependent carbon fixation pathway roTCA cycle in anaerobic bacteria $[15,16]$, it became interesting to reassess more carefully the chemolithoautotrophic potential of G. sulfurreducens PCA. Like multiple other bacteria, G. sulfurreducens PCA's genome codes for the full complement of enzymes necessary for TCA cycles in anaerobes (Fig. 1a). Furthermore, the activity of most of these enzymes has already been demonstrated (Table S3) [21, 54]. The complete components of TCA cycle and the capability of hydrogenoxidizing metabolism in G. sulfurreducens PCA suggest the genomic capability of roTCA cycle while chemolithoautotrophic growth was not observed in this strain.

To assess if G. sulfurreducens PCA has a chemolithoautotrophic capability harbored in its genome, an ALE experiment was initiated where the bacterial culture was transferred serially into $\mathrm{FcF}$ medium. The medium contains the $\mathrm{C} 1$ compound formate as the electron donor and carbon source and Fe(III) citrate as the electron acceptor. Fe(III), an electron acceptor of Geobacter spp., is commonly supplemented as $\mathrm{Fe}(\mathrm{III})$ citrate, and growth and isotope tracing experiments have established that citrate is not used as a carbon source of $G$. sulfurreducens $[26,55,56]$. These results are to be expected since no bacterial transporter demonstrated experimentally to be capable of citrate uptake are encoded on the genome of G. sulfurreducens [30]. Furthermore, G. sulfurreducens reduces Fe(III) outside of 

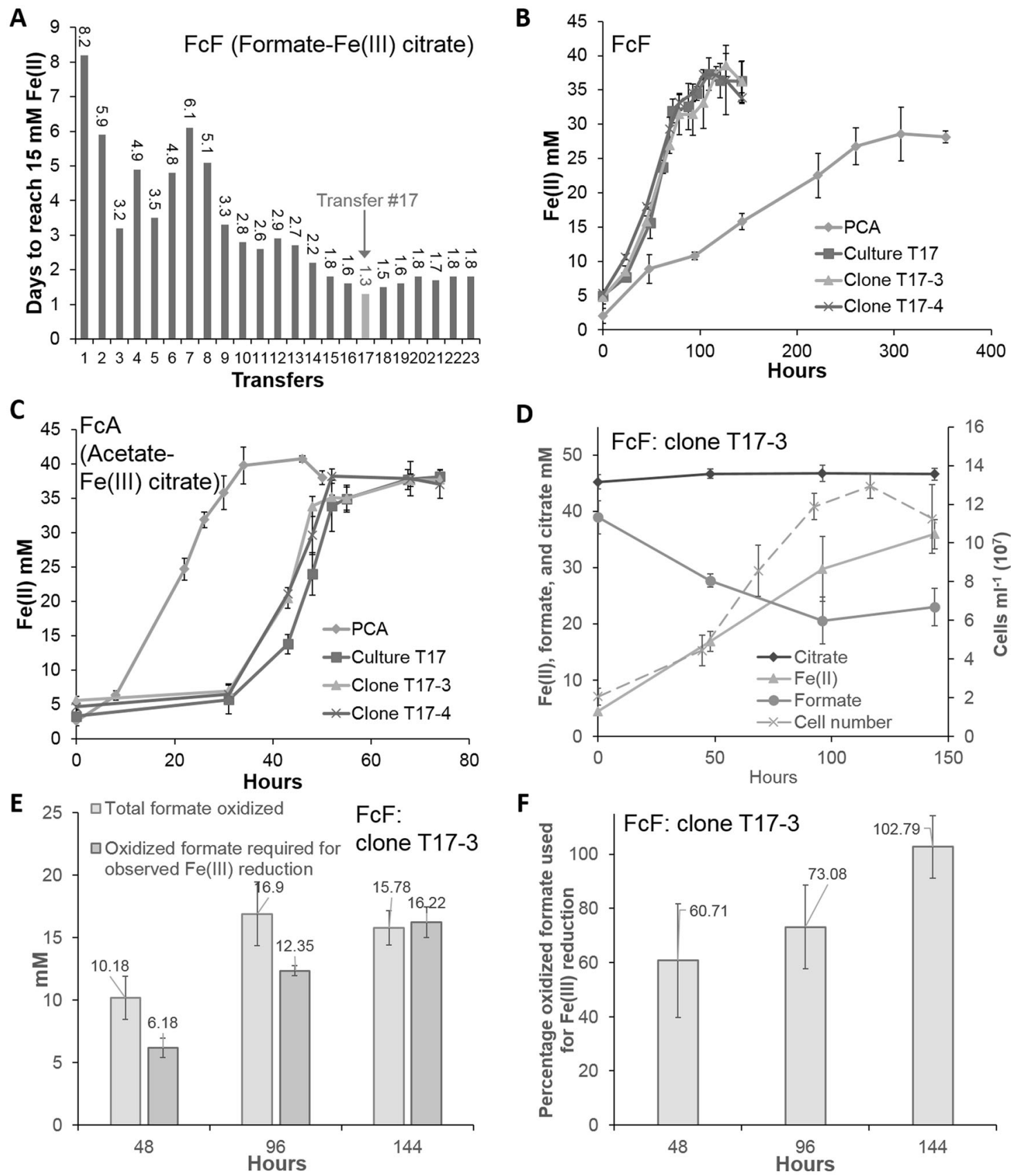

\section{$\mathbf{F}$}

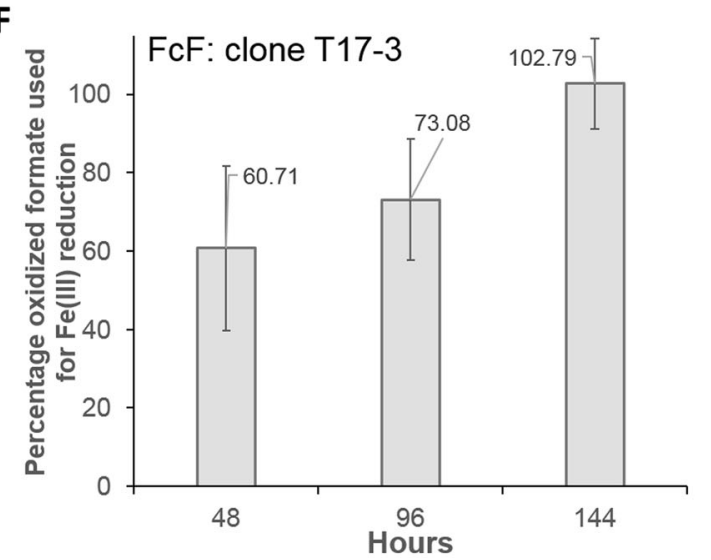

Fig. 2 Adaptation, growth, and metabolism of G. sulfurreducens PCA with formate as carbon source and electron donor as well as $\mathrm{Fe}$ (III) citrate as electron acceptor. a Number of days to reach 15 $\mathrm{mM} \mathrm{Fe}$ (II) for each transfer during the ALE experiment with FcF medium. b Growth of PCA, the FcF-adapted culture T17, the clones T17-3, and T17-4 on FcF medium and c FcA medium. d Fe(III) reduction, formate oxidation, citrate concentration, and cell count increase when clone T17-3 grew in $\mathrm{FcF}$ medium. e Total formate

the cell at the outer surface and does not have homologs for the $\mathrm{Fe}$ (III) citrate transporter complex FecABCDE found in other Gram-negative bacteria such as E. coli [57, 58].

The first transfer into $\mathrm{FcF}$ was from an acetate-grown PCA culture in an $\mathrm{Fc}$ medium with acetate as electron donor

consumed, oxidized formate equivalent required for observed Fe(III) reduction and $\mathbf{f}$ percentage of oxidized formate used for $\mathrm{Fe}(\mathrm{III})$ reduction at 48,96 , and $144 \mathrm{~h}$ by $\mathrm{T} 17-3$ in $\mathrm{FcF}$ medium. Formate is oxidized in G. sulfurreducens according to the reaction $\mathrm{HCOO}^{-} \rightarrow$ $\mathrm{CO}_{2}+\mathrm{H}^{+}+2 \mathrm{e}^{-}$. $\mathrm{Fe}(\mathrm{III})$ is reduced in G. sulfurreducens according to the reaction $\mathrm{Fe}^{3+}+\mathrm{e}^{-} \rightarrow \mathrm{Fe}^{2+}$. Overall, 1 mol formate reduces $2 \mathrm{~mol}$ $\mathrm{Fe}(\mathrm{III})$. Each curve and bar for $\mathbf{b}-\mathbf{f}$ is the mean of three replicates with standard deviation.

and organic carbon source and $\mathrm{Fe}(\mathrm{III})$ as electron acceptor. This $15 \%$ transfer required 8.2 days to reach $15 \mathrm{mM}$ Fe(II) in FcF medium (Fig. 2a). Subsequently, a 15\% inoculum from the first $\mathrm{FcF}$ culture was transferred into fresh $\mathrm{FcF}$ medium for the second transfer, which took 5.9 days to 

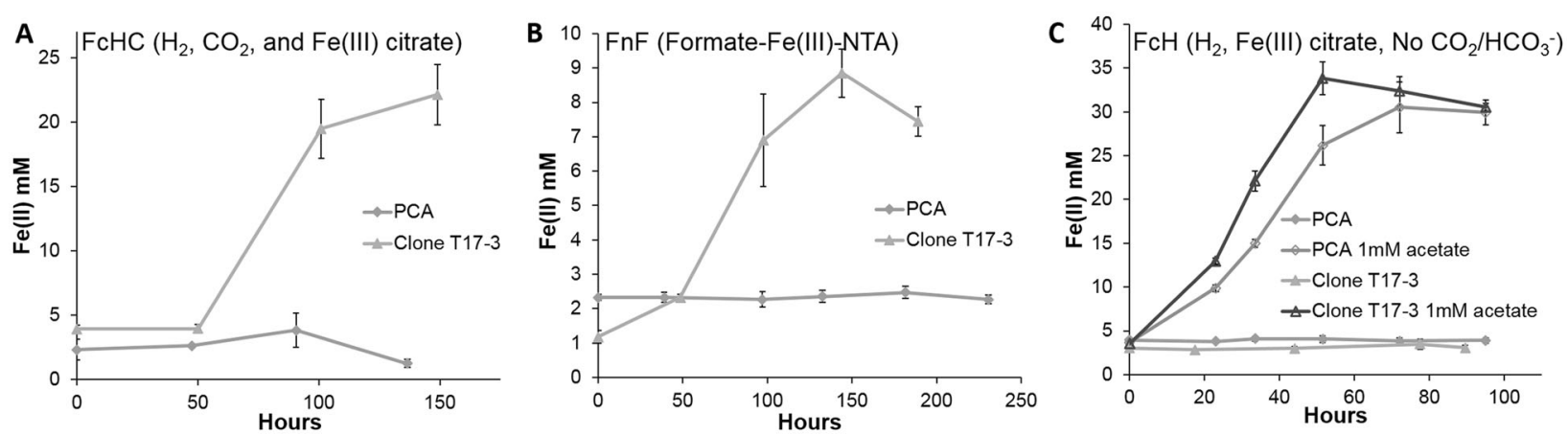

Fig. 3 G. sulfurreducens T17-3 growth with alternative carbon sources, electron donors, and acceptors. a Fe(III) reduction by PCA and $\mathrm{T} 17-3$ in an FcHC medium with $\mathrm{H}_{2}$ as electron donor, $\mathrm{CO}_{2}$ as carbon source, and $\mathrm{Fe}(\mathrm{III})$ citrate as electron acceptor. b $\mathrm{Fe}(\mathrm{III})$ reduction by $\mathrm{PCA}$ and $\mathrm{T} 17-3$ in an $\mathrm{FnF}$ medium with formate as electron donor and carbon source and $\mathrm{Fe}(\mathrm{III})$-NTA as electron

reach $15 \mathrm{mM} \mathrm{Fe}(\mathrm{II})$. After five transfers in $\mathrm{FcF}$, acetate concentration was measured at the beginning of transfer 6 and no residual acetate from the initial FcA culture was detected. After ten transfers in FcF fresh medium, the PCA culture was clearly adapting and required only 2.8 days to reach $15 \mathrm{mM} \mathrm{Fe(II).} \mathrm{The} \mathrm{Fe}(\mathrm{III})$ reduction rate of the adapted PCA culture became stabilized after transfer 15 and did not improve significantly afterward. The ALE experiment was stopped at transfer 23. Culture from transfer 17, which reached $15 \mathrm{mM} \mathrm{Fe(II)} \mathrm{after} 1.3$ days, was used for further experiments.

To obtain individual clonal population, colonies were isolated from the T17 culture and tested for $\mathrm{Fe}(\mathrm{III})$ reduction in FcF medium. Culture T17, clones T17-3 and T17-4 reduced $\mathrm{Fe}(\mathrm{IIII})$ at a rate of $490.3 \pm 23.0,417.5 \pm 54.0$, and $414.3 \pm 21.5 \mu \mathrm{M} \mathrm{h}^{-1}$, respectively (Fig. 2b). In comparison, unadapted PCA after one transfer from $\mathrm{FcA}$ to $\mathrm{FcF}$ reduced $\mathrm{Fe}(\mathrm{III})$ at a rate of $94.3 \pm 23.0 \mu \mathrm{M} \mathrm{h}^{-1}$, which was 5.2 times slower than culture T17. When grown on FcA, culture T17 and derived clones had significantly longer lag phase than PCA, which showed that gain of fitness when growing chemolithoautotrophically with formate was accompanied with a loss of fitness for heterotrophic growth with acetate as substrate (Fig. 2c).

\section{Cell count, formate oxidation, citrate concentration, and $\mathrm{Fe}(\mathrm{III})$ reduction}

To confirm that adapted bacteria grow in $\mathrm{FcF}$ medium and not only reduce $\mathrm{Fe}(\mathrm{III}), \mathrm{T} 17-3$ cells were counted at different time points over a period of $143 \mathrm{~h}$ after inoculation (Fig. 2d). From 45 to $93 \mathrm{~h}$, the cell number in the $\mathrm{FcF}$ medium increased by $7.45 \times 10^{7} \pm 1.05 \times 10^{7}$ cells ml ${ }^{-1}$ $(n=3)$. In comparison, increase in T17-3 cell number was negligible when no formate was provided (Fig. S1). The results demonstrated that $\mathrm{Fe}(\mathrm{III})$ reduction with formate as acceptor. c Fe(III) reduction by PCA and T17-3 in an FcH medium without inorganic carbon $\mathrm{CO}_{2} / \mathrm{HCO}_{3}{ }^{-}$, with $\mathrm{H}_{2}$ as electron donor, $\mathrm{Fe}$ (III) citrate as electron acceptor, and MOPS as buffer in the presence or not of $1 \mathrm{mM}$ acetate. Each curve is the mean of three replicates with standard deviation.

energy and carbon sources was accompanied with cell biosynthesis, division, and growth. When formate consumption ceased, T17-3 cell number stopped increasing and eventually decreased, which indicates the end of biosynthesis and the beginning of cell death.

Besides $\mathrm{Fe}(\mathrm{III})$ reduction and cell number increase, formate concentration was also monitored during growth of the T17-3 clone (Fig. 2d). During exponential growth phase, more formate than required for the observed $\mathrm{Fe}(\mathrm{III})$ reduction was consumed by the T17-3 clone (Fig. 2e, f). Only $60.7 \pm 21.0 \%$ and $73.1 \pm 15.5 \%$ of all the electrons derived from formate consumed by cells after 48 and $96 \mathrm{~h}$ of growth, respectively, were used for energy conservation via $\mathrm{Fe}(\mathrm{III})$ reduction. During the stationary growth phase from 96 to $144 \mathrm{~h}$, formate consumption ceased while $\mathrm{Fe}(\mathrm{III})$ reduction continued at a slower rate compared with 0 to 96 h. After $144 \mathrm{~h}$, all the electrons derived from oxidized formate have been employed for Fe(III) reduction (Fig. 2e, f). In the absence of formate oxidation in the stationary growth phase, it is highly possible that T17-3 cell starts reducing Fe (III) with electrons coming from substrates excreted by cells, from metabolites released by dead cells or from compounds stored beforehand in cell reserve.

In G. sulfurreducens, formate is oxidized (formate $\rightarrow$ $\mathrm{CO}_{2}+\mathrm{H}^{+}+2 \mathrm{e}^{-}, E_{0}^{\prime}=-420 \mathrm{mV}$ ) by the periplasmically oriented membrane-bound formate dehydrogenase FdnGHI [59]. For chemolithoautotrophic growth on formate as substrate to be feasible, part of the electrons generated by the oxidation reaction catalyzed by the formate dehydrogenase must be carried by the electron transport chain to the final electron acceptor $\mathrm{Fe}$ (III), while protons released in the periplasm form the proton gradient necessary for energy conservation. Concomitantly, another fraction of electrons coming from formate oxidation must be used for the metabolic reduction of $\mathrm{CO}_{2}$ required for the synthesis of cell components. Both formate consumption and $\mathrm{Fe}$ (III) 

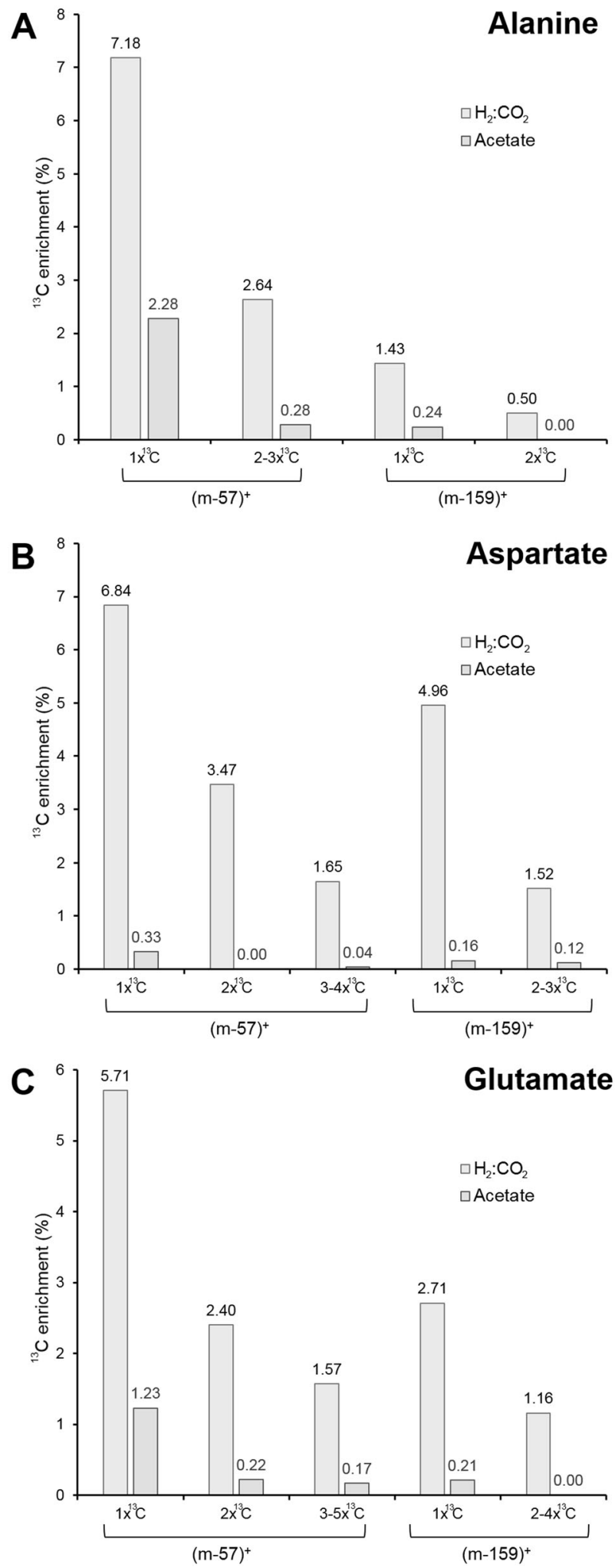

Fig. 4 Isopotomer analysis of $G$. sulfurreducens $\quad$ T17-3. ${ }^{13} \mathrm{C}$ enrichments of $\mathbf{a}$ alanine, $\mathbf{b}$ aspartate, and $\mathbf{c}$ glutamate mass fragments from $G$. sulfurreducens T17-3 grown either chemolithoautrophically or heterotrophically with $\mathrm{H}^{13} \mathrm{CO}_{3}{ }^{-}$. (M-57) ${ }^{+}$is the ${ }^{13} \mathrm{C}$ enrichment of the entire amino acids while $(\mathrm{m}-159)^{+}$is the amino acid without the $\alpha$ carboxyl group. $n \times{ }^{13} \mathrm{C}$ or $n-y \times{ }^{13} \mathrm{C}$ indicates the presence of $n{ }^{13} \mathrm{C}$ or $n$ to $y{ }^{13} \mathrm{C}$ in the amino acid, respectively. reduction results during the exponential growth phase of strain T17-3 support this dual metabolism where formate is used simultaneously as a substrate for biosynthesis and as an electron donor for energy conservation.

Besides formate, the $\mathrm{C} 6$ organic carbon compound citrate is also present in the $\mathrm{FcF}$ medium under the form of $\mathrm{Fe}$ (III) citrate. Although a large number of evidences demonstrated that $\mathrm{Fe}(\mathrm{III})$ citrate is not used as a carbon source by $G$. sulfurreducens $[26,55,56]$, the citrate concentration was monitored during growth (Fig. 2d). From time 0 to $144 \mathrm{~h}$, citrate concentration did not change, which suggested that it was not used by strain T17-3.

\section{Chemolithoautotrophic growth of G. sulfurreducens T17-3 with alternative substrates}

To provide additional evidences of chemolithoautotrophic metabolism, adapted strain T17-3 was also cultivated with $\mathrm{H}_{2}$ as electron donor, $\mathrm{CO}_{2}$ as carbon source and $\mathrm{Fe}(\mathrm{III})$ citrate as electron acceptor ( $\mathrm{FcHC})$, as well as with formate as electron donor and carbon source and $\mathrm{Fe}$ (III)-NTA as electron acceptor (FnF) (Fig. 3a, b). Before collecting data for $\mathrm{Fe}(\mathrm{III})$ reduction curves with T17-3, four prior transfers on either FcHC or FnF were carried out from an original $\mathrm{FcF}$ inoculum to ensure complete depletion of carbon sources, electron donors, and acceptors found in FcF medium. Fe(III) reduction curves with PCA were done with the second transfer on FcHC or FnF from an FcA culture. T173 grew in $\mathrm{FcHC}$ at a $\mathrm{Fe}(\mathrm{III})$ reduction rate of $346.9 \pm 57.3$ $\mu \mathrm{M} \mathrm{h}^{-1}$ between 50 and $100 \mathrm{~h}$ and significant increase of cell number while PCA did not reduce $\mathrm{Fe}(\mathrm{III})$ over an incubation period of $144 \mathrm{~h}$ (Fig. S1). In addition, citrate concentration was also assessed during chemolithoautotrophic growth of T17-3 in FcHC medium (Fig. S2). Similar to the results from $\mathrm{FcF}$, citrate concentration did not vary in FcHC medium. For FnF growth, T17-3 had a Fe(III) reduction rate of $95.7 \pm 29.7 \mu \mathrm{M} \mathrm{h}^{-1}$, while G. sulfurreducens PCA did not reduce Fe(III)-NTA over $230 \mathrm{~h}$ (Fig. 3b). These results demonstrated that chemolithoautotrophic growth by G. sulfurreducens T17-3 is not specific to formate and $\mathrm{Fe}(\mathrm{III})$ citrate, but is also observed with $\mathrm{CO}_{2}$ as carbon source, $\mathrm{H}_{2}$ as electron donor, and $\mathrm{Fe}(\mathrm{III})$-NTA as electron acceptor.

\section{Removal of $\mathrm{CO}_{2}$ and $\mathrm{HCO}_{3}{ }^{-}$prevents $\mathrm{H}_{2}$-driven growth of T17-3}

Chemolithoautotrophic capability of $G$. sulfurreducens T17-3 was further investigated by growing cells in an $\mathrm{FcH}$ medium with $\mathrm{H}_{2}$ as the electron donor and $\mathrm{Fe}$ (III) citrate as the electron acceptor, but where $\mathrm{CO}_{2}$ and $\mathrm{HCO}_{3}{ }^{-}$had been removed from the gas phase and the liquid phase (Fig. 3c). An MOPS buffer was added in this growth medium to 
replace the bicarbonate buffer system and maintain $\mathrm{pH}$ to 7.0. Neither PCA nor T17-3 could grow in the absence of $\mathrm{CO}_{2} / \mathrm{HCO}_{3}{ }^{-}$providing further evidence that the formate adaptation process activated a chemolithoautotrophic metabolism in T17-3 dependent on the presence of inorganic carbon sources. When $1 \mathrm{mM}$ acetate was provided as carbon source with the MOPS-based FcH medium, both PCA and T17-3 reduced Fe(III) at a rate of $577.3 \pm 73.8$ and $724.3 \pm 56.8 \mu \mathrm{M} \mathrm{Fe}(\mathrm{II}) \mathrm{h}^{-1}$, respectively.

\section{Isopotomer analysis of chemolithoautotrophic growth with $\mathrm{H}^{13} \mathrm{CO}_{3}{ }^{-}$}

To investigate if the roTCA cycle was active in the adapted strain T17-3, $6 \mathrm{mM} \mathrm{H}^{13} \mathrm{CO}_{3}{ }^{-}$was added to mid$\log$ phase cultures growing either chemolithoautotrophically with $\mathrm{FcHC}$ or heterotrophically with FcA. Sixteen hours after the addition of ${ }^{13} \mathrm{C}$, cells were harvested, hydrolyzed, and proteinogenic amino acids were derivatized for isotopologue profiling by GC-MS (Fig. S3). ${ }^{13} \mathrm{C}$ enrichments of entire amino acids $(\mathrm{m}-57)^{+}$ and amino acids lacking the $\alpha$-carboxyl group $(\mathrm{m}-159)^{+}$ were analyzed to determine ${ }^{13} \mathrm{C}$ position [60]. Alanine, aspartate, and glutamate were selected for the isopotologue analysis since they are synthesized from precursors generated by the TCA cycles [56].

${ }^{13} \mathrm{C}$ enrichment of all three amino acids in $\mathrm{H}_{2}: \mathrm{CO}_{2}$-grown cells compared with acetate-grown cells indicated that the roTCA cycle was functional in T17-3 (Figs. 4 and S4). For alanine, ${ }^{13} \mathrm{C}$ labeling of $\mathrm{C} 1$ indicated carboxylation of acetyl-CoA by PFOR for both acetate-grown and $\mathrm{H}_{2}: \mathrm{CO}_{2}-$ grown cells. Carboxylation of acetyl-CoA by PFOR is a contributing gluconeogenetic reaction for the biosynthetic metabolism of $G$. sulfurreducens during growth with acetate as carbon source and $\mathrm{Fe}$ (III) as electron acceptor [56]. However, it was only with $\mathrm{H}_{2}$ : $\mathrm{CO}_{2}$-grown cells that a significant fraction of alanine was labeled with two to three ${ }^{13} \mathrm{C}$ (Fig. 4a). This result shows that pyruvate molecules, the precursor of alanine, were synthesized with at least two inorganic carbon molecules probably via the roTCA cycle.

Aspartate and glutamate molecules with ${ }^{13} \mathrm{C}$ were also significantly more frequent when T17-3 was grown chemolithoautotrophically (Fig. 4b). Precursors for aspartate and glutamate are oxaloacetate and 2-oxoglutarate, respectively. The isotopologue profile for aspartate showed that both PFOR and the pyruvate carboxylase carboxylated acetyl-CoA into oxaloacetate. Furthermore, the detection of aspartate molecules labeled with three or four ${ }^{13} \mathrm{C}$ indicated that oxaloacetate underwent multiple turns in the roTCA cycle. ${ }^{13} \mathrm{C}$ enrichment and position in glutamate molecules from T17-3 grown with $\mathrm{H}_{2}: \mathrm{CO}_{2}$ versus acetate provides additional evidences of the activity of the roTCA cycle in the adapted strain (Fig. 4c).

\section{Mutations in G. sulfurreducens T17-3 and T17-4}

The genomes of formate-adapted clones T17-3 and T17-4 were sequenced to gain insights on how G. sulfurreducens evolved to grow chemolithoautotrophically in $\mathrm{FcF}$ (Table S4). T17-3 and T17-4 had a total of 15 singlenucleotide polymorphisms (SNP), 1 insertion, and 2 deletions in common. One SNP was exclusive to T17-4. Mutations were located in or near genes coding for hypothetical proteins, membrane proteins, $c$-type cytochromes, and enzymes involved in RNA methylation, oxidoreduction, glycerophospholipid metabolism, nucleotide salvage, and branched-chain amino acid catabolism. $d c u B$, the gene coding for the anaerobic C4-dicarboxylate transporter essential for the growth of Geobacter spp. with fumarate as electron acceptor [61], was mutated with an SNP resulting in the substitution of tyrosine-385 for a histidine. However, this mutation had no major impact since the adapted strains T17-3 and T17-4 could still grow with fumarate as electron acceptor (Fig. S5).

rров, the gene coding for the $\beta$-subunit of the RNA polymerase, had an SNP resulting in the substitution of glutamine-1089 by an arginine in the C-terminal part of the protein (Table S4) [62]. Mutations in rpoB or in other global transcription-related genes have been observed in multiple ALE experiments where they have major beneficial impacts on fitness by affecting simultaneously the expression of hundreds to thousands of genes [63-65]. These important changes in the expression profile usually lead to pleiotropic effects on cell's function [66, 67]. Here, genome sequencing results suggest that $r p o B$ mutation is involved in the capacity of G. sulfurreducens to adapt and grow chemolithoautotrophically on formate.

\section{Role of the succinyl-CoA synthetase in the adapted strain}

Among the 19 mutations found by whole-genome sequencing, one SNP in T17-3 and T17-4 was located upstream of GSU0514, which is a gene that has been shown to have a direct regulatory impact on the oTCA cycle of G. sulfurreducens. GSU0514 is a transcriptional regulator of the IclR family involved in the repression of the transcription of $\operatorname{suc} C D$, the two genes coding for the succinyl-coA synthetase, which is a central enzyme of the oTCA cycle [42] as well as of the roTCA and rTCA cycles $[1,15]$. In $G$. sulfurreducens PCA grown with acetate as substrate, the conversion of acetate into acetyl-CoA prior to oxidation via oTCA is achieved by the succinylCoA:acetate CoA-transferase, which does not require ATP hydrolysis contrary to the alternative pathway catalyzed by an acetate kinase and a phosphotransacetylase (Fig. 1b) [21, 54]. When the succinyl-CoA:acetate 
CoA-transferase is active, the succinyl-CoA synthetase is not required for the completion of the oTCA cycle. This has been highlighted by the absence of succinyl-coA synthetase activity in G. sulfurreducens growing heterotrophically [21, 54]. Since G. sulfurreducens is usually maintained with acetate as substrate in laboratory conditions, the bacterium has adapted and optimized its acetate metabolism by repressing the expression of succinyl-CoA synthetase via a GSU0514-dependent regulatory mechanism.

However, when acetate is not available in sufficient quantity for the succinyl-CoA:acetate CoA-transferase, $G$. sulfurreducens must adapt and reoptimize its metabolism to ensure efficient growth. This has been demonstrated by adapting G. sulfurreducens to grow on lactate as sole substrate [42]. After serial transfer of G. sulfurreducens PCA on lactate, mutations inactivating GSU0514 appeared and the expression of the genes coding for the succinyl-coA synthetase had a multifold increase. For chemolithoautotrophic growth of G. sulfurreducens with formate or other $\mathrm{C} 1$ compounds, the succinyl-CoA synthetase would be required for the completion of a functional roTCA cycle, which may explain the mutation found upstream of GSU0514 in T17-3 and T17-4.

The SNP A $\rightarrow$ G was found in position -161 in relation to the start of the coding sequence of GSU0514 and was localized in the -35 box of the promoter of GSU0514 as predicted by BPROM (Fig. S6) [68]. Quantitative PCR showed that GSU0514 was downregulated 3.6-fold (3.4-3.8) in T17-3 grown with formate compared with PCA grown with acetate (Fig. 5a). Concomitantly, sucC, the gene coding for the $\beta$-subunit of the succinyl-CoA synthetase, was upregulated fivefold (4.2-6.0) in T17-3 grown in FcF compared with PCA grown in FcA. The enzymatic activity of succinyl-CoA synthetase was also measured by monitoring the formation of succinyl-CoA from succinate, ATP, and CoA in whole-cell lysates of T17-3 grown in $\mathrm{FcF}$ and PCA grown in FcA (Fig. 5b) [69]. A barely detectable succinyl-CoA synthetase activity of $4.81 \pm 2.69 \mathrm{nmol}$ succinyl-CoA $\min ^{-1} \mathrm{mg}$ per protein was measured in PCA grown in FcA. In comparison, succinyl-CoA synthetase activity in T17-3 grown in $\mathrm{FcF}$ was 3.4-fold higher at $16.41 \pm 2.86 \mathrm{nmol}$ succinyl-CoA $\min ^{-1} \mathrm{mg}$ per protein.

Furthermore, deletion in the adapted strain T17-3 of both sucC and $s u c D$, the gene coding for the $\alpha$-subunit of the succinyl-CoA synthetase, prevented growth in FcF but not in FcA medium (Fig. 5c). The absence of a functional succinyl-CoA synthetase appears to disrupt the roTCA cycle, which inhibits chemolithoautotrophic growth by $G$. sulfurreducens. This result confirms the importance of the SNP upstream of GSU0514 for the adaptation of G. sulfurreducens to grow with formate as substrate.

\section{Activity of the citrate synthase in the reductive direction}

The CS is a key enzyme catalyzing an essential step of the oTCA cycle in the oxidative direction and of the roTCA cycle in the reductive direction (Fig. 1). In G. sulfurreducens PCA, activity of the CS GltA in the oxidative direction where free $\mathrm{CoA}$ and citrate are formed by the condensation of acetylCoA and oxaloacetate has already been observed [54]. However, GltA must catalyze the reverse ATP-independent conversion of citrate and CoA into acetyl-CoA and oxaloacetate for the roTCA cycle to be functional. This activity has never been demonstrated before in G. sulfurreducens. Here, GltA activity in the reductive direction was coupled with porcine malate dehydrogenase and NADH oxidation was monitored [15]. The reductive CS activity in the whole-cell lysate of PCA grown in FcA was $102.87 \pm 1.97$ nmol NAD $^{+}$ $\mathrm{min}^{-1} \mathrm{mg}$ per protein (Fig. 5d). In the adapted strain T17-3 grown in FcF, CS activity was still detected but lower at $40.19 \pm 1.97 \mathrm{nmol} \mathrm{NAD}^{+} \mathrm{min}^{-1} \mathrm{mg}$ per protein. Quantitative PCR results are in line with enzymatic activity. gltA was expressed 5.1 (4.0-6.4) times less in $\mathrm{T} 17-3$ grown in $\mathrm{FcF}$ compared with PCA grown in FcA (Fig. 4a).

The lower activity and transcription of CS in T17-3 grown in formate is to be expected if we consider that CS participates into the roTCA cycle during chemolithoautotrophic growth with formate, and its main function is the biosynthesis of cell components from $\mathrm{CO}_{2}$. While during heterotrophic growth on acetate, CS participates into the oTCA cycle, and its principal function is to release energy stored in organic carbon substrate for respiration. Thus, metabolic flux is likely to be more important through CS in an oxidative context for respiration than in a reductive context for biosynthesis and, under these circumstances, the cell may limit energy expense by decreasing CS expression.

\section{Discussion}

Genome annotation have led to the suggestion that Geobacter bemidjiensis has a chemolithoautotrophic metabolism via the rTCA cycle [70]. Growth experiment showed that another Geobacter species, Geobacter metallireducens, can grow chemolithoautotrophically, and based on genome annotation, it has been suggested that either the rTCA or the dicarboxylate-4-hydroxybutyrate cycles are involved [71]. The discovery of the roTCA cycle $[15,16]$ as well as experimental evidences presented here demonstrating chemolithoautotrophic growth via roTCA cycle by $G$. sulfurreducens raise the possibility that carbon fixation capability is more widespread than previously thought in the Geobacteraceae family. Genes coding for CS and other enzymes of the o/roTCA cycles are present in the vast 

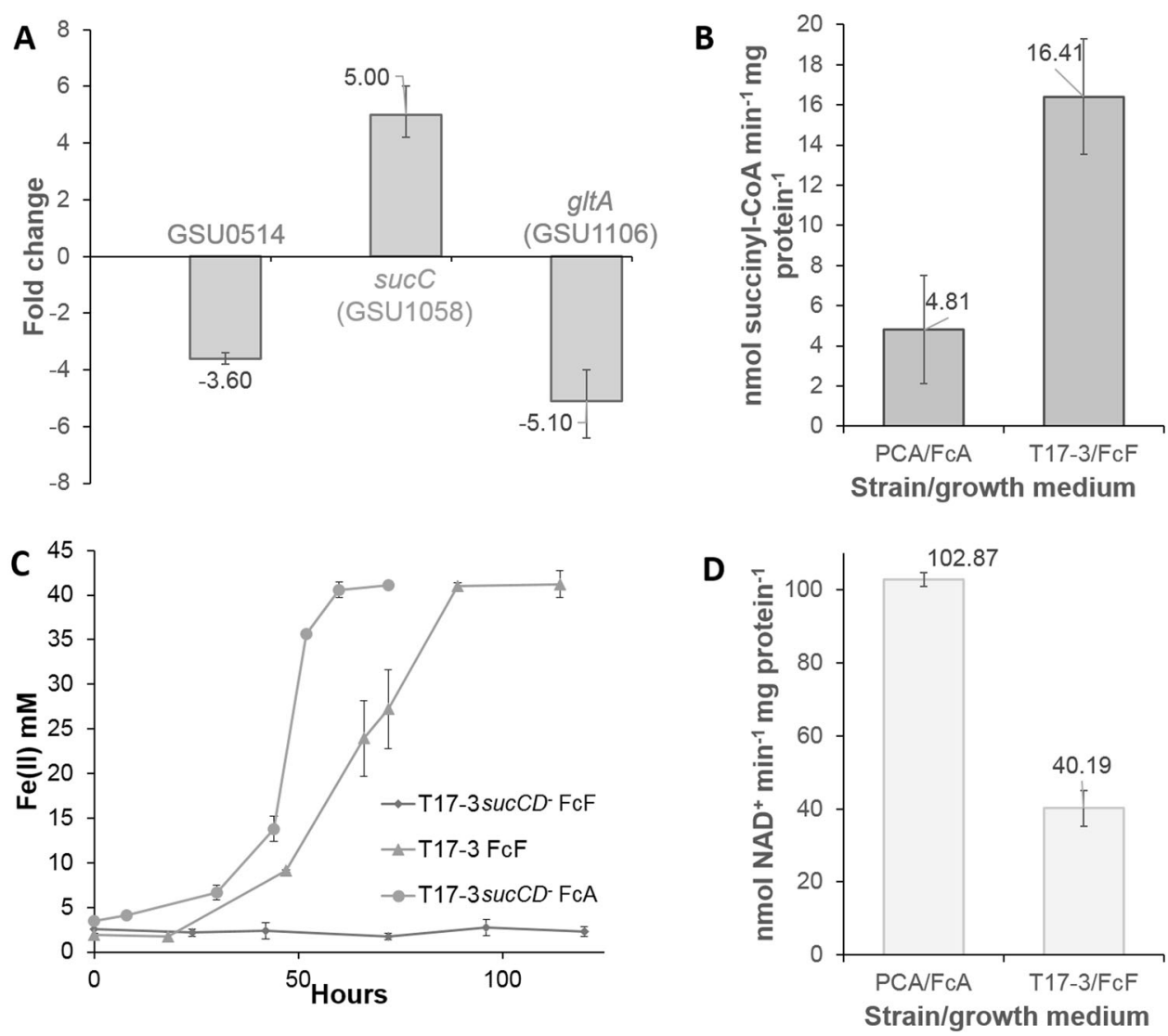

Fig. 5 Transcript abundance fold change of succinyl-CoA synthetase and citrate synthase genes, enzymatic activities, and growth of the T17-3 sucCD ${ }^{-}$mutant. a Transcript abundance fold change of GSU0514, sucC, and gltA in strain T17-3 grown in $\mathrm{FcF}$ medium compared with PCA grown in FcA medium. b Enzymatic activity of the succinyl-CoA synthetase (SucCD). Succinyl-CoA synthetase activity was measured via the formation of succinyl-CoA from succinate according to the reaction succinate $+\mathrm{CoA}+\mathrm{ATP} \rightarrow$

majority of Geobacter species genomes sequenced until now and this includes G. bemidjiensis and G. metallireducens. When compared with the rTCA and the dicarboxylate-4-hydroxybutyrate cycles, the roTCA cycle appears to be more efficient bioenergetically [15]. Thus, $G$. bemidjiensis and G. metallireducens thought to reduce $\mathrm{CO}_{2}$ via alternative carbon fixation pathways may also use the roTCA cycle concomitantly or preferentially.

Several recent studies show that Geobacter spp. have a chemolithoautotrophic metabolism [70, 71]. Based on these developments, the ecological niche of Geobacter species as degraders of organic acid substrates released by fermentative microbes may have to be reconsidered. At the very least, the chemolithoautotrophic capacity of Geobacter spp. confers a competitive advantage over other species and may explain why this family can maintain itself in habitats where organic carbon substrates are likely to fluctuate $[18,19]$.

In addition, the chemolithoautotrophic metabolism of $G$. sulfurreducens is intriguing for potential industrial
succinyl-CoA + ADP. c Growth of the T17-3 sucCD $D^{-}$mutant on $\mathrm{FcF}$ and FcA medium. d Enzymatic activity of CS (GltA) in whole-cell lysates of PCA grown in FcA and of T17-3 grown in FcF. CS activity was measured via oxaloacetate formation coupled with porcine malate dehydrogenase for NADH oxidation according to the following reactions: (1) citrate $+\mathrm{CoA} \rightarrow$ acetyl-CoA + oxaloacetate and (2) oxaloacetate $+\mathrm{NADH}+\mathrm{H}^{+} \rightarrow$ malate $+\mathrm{NAD}^{+}$. The results shown are from at least three replicates for each experiment with standard deviation.

applications since this bacterium can synthesize bioelectronic compounds such as electrically conductive pili and can be employed as microbial catalyst in bioelectrochemical systems [26, 72]. Thus, bioproduction processes catalyzed by $G$. sulfurreducens could be driven by microbial electrosynthesis or could be optimized for the synthesis of bioelectronic parts from the greenhouse gas $\mathrm{CO}_{2}$.

Furthermore, another interesting observation reported here is that an anaerobic bacterial species previously thought to be a strict heterotroph has a chemolithoautotrophic metabolic capacity that was revealed by ALE. G. sulfurreducens PCA was isolated in the laboratory with acetate as electron donor and carbon source [31]. This isolation method might have introduced metabolic biases and adaptive mutations hiding physiological functions with major role in the natural habitat of the isolated microbe. Based on the observation here, it is possible that other laboratory-isolated anaerobic microbes with genes for the roTCA cycle have been characterized prematurely as strict heterotroph. 
Acknowledgements This work was supported by the Chinese Thousand Talents Plan Program and Wuhan University of Technology.

\section{Compliance with ethical standards}

Conflict of interest The authors declare that they have no conflict of interest.

Publisher's note Springer Nature remains neutral with regard to jurisdictional claims in published maps and institutional affiliations.

\section{References}

1. Fuchs G. Alternative pathways of carbon dioxide fixation: insights into the early evolution of life? Annu Rev Microbiol. 2011;65:631-58

2. Hügler M, Sievert SM. Beyond the Calvin cycle: autotrophic carbon fixation in the ocean. Ann Rev Mar Sci. 2011;3:261-89.

3. Evans MC, Buchanan BB, Arnon DI. A new ferredoxindependent carbon reduction cycle in a photosynthetic bacterium. Proc Natl Acad Sci USA. 1966;55:928-34.

4. Fuchs G, Stupperich E, Eden G. Autotrophic $\mathrm{CO}_{2}$ fixation in Chlorobium limicola. Evidence for the operation of a reductive tricarboxylic acid cycle in growing cells. Arch Microbiol. 1980;128:64-71

5. Schauder R, Widdel F, Fuchs G. Carbon assimilation pathways in sulfate-reducing bacteria II. Enzymes of a reductive citric acid cycle in the autotrophic Desulfobacter hydrogenophilus. Arch Microbiol. 1987;148:218-25.

6. Shiba H, Kawasumi T, Igarashi Y, Kodama T, Minoda Y. The $\mathrm{CO}_{2}$ assimilation via the reductive tricarboxylic acid cycle in an obligately autotrophic, aerobic hydrogen-oxidizing bacterium, Hydrogenobacter thermophilus. Arch Microbiol. 1985;141:198-203.

7. Ivanovsky RN, Sintsov NV, Kondratieva EN. ATP-linked citrate lyase activity in the green sulfur bacterium Chlorobium limicola forma thiosulfatophilum. Arch Microbiol. 1980;128:239-41.

8. Aoshima M, Ishii M, Igarashi Y. A novel enzyme, citryl-CoA synthetase, catalysing the first step of the citrate cleavage reaction in Hydrogenobacter thermophilus TK-6. Mol Microbiol. 2004;52:751-61.

9. Aoshima M, Ishii M, Igarashi Y. A novel enzyme, citryl-CoA lyase, catalysing the second step of the citrate cleavage reaction in Hydrogenobacter thermophilus TK-6. Mol Microbiol. 2004;52:763-70.

10. Kanao T, Fukui T, Atomi H, Imanaka T. ATP-citrate lyase from the green sulfur bacterium Chlorobium limicola is a heteromeric enzyme composed of two distinct gene products. Eur J Biochem. 2001;268:1670-8.

11. Beh M, Strauss G, Huber R, Stetter K-O, Fuchs G. Enzymes of the reductive citric acid cycle in the autotrophic eubacterium Aquifex pyrophilus and in the archaebacterium Thermoproteus neutrophilus. Arch Microbiol. 1993;160:306-11.

12. Berg IA. Ecological aspects of the distribution of different autotrophic $\mathrm{CO}_{2}$ fixation pathways. Appl Environ Microbiol. 2011;77:1925-36.

13. Thauer RK, Möller-Zinkhan D, Spormann AM. Biochemistry of acetate catabolism in anaerobic chemotrophic bacteria. Annu Rev Microbiol. 1989;43:43-67.

14. Ito S, Koyama N, Osanai T. Citrate synthase from Synechocystis is a distinct class of bacterial citrate synthase. Sci Rep. 2019;9:6038.

15. Mall A, Sobotta J, Huber C, Tschirner C, Kowarschik S, Bačnik $\mathrm{K}$, et al. Reversibility of citrate synthase allows autotrophic growth of a thermophilic bacterium. Science. 2018;359:563-7.
16. Nunoura T, Chikaraishi Y, Izaki R, Suwa T, Sato T, Harada T, et al. A primordial and reversible TCA cycle in a facultatively chemolithoautotrophic thermophile. Science. 2018;359:559-63.

17. Ragsdale SW. Stealth reactions driving carbon fixation. Science. 2018;359:517-8.

18. Lovley DR, Ueki T, Zhang T, Malvankar NS, Shrestha PM, Flanagan KA, et al. Geobacter: the microbe electric's physiology, ecology, and practical applications. Adv Micro Physiol. 2011;59:1-100.

19. Röling WFM. The family Geobacteraceae. In: Rosenberg E, DeLong EF, Lory S, Stackebrandt E, Thompson F, editors. The prokaryotes: Deltaproteobacteria and Epsilonproteobacteria. Berlin, Heidelberg: Springer Berlin Heidelberg; 2014. p. 157-72.

20. Mahadevan R, Bond DR, Butler JE, Esteve-Nuñez A, Coppi MV, Palsson BO, et al. Characterization of metabolism in the Fe(III)reducing organism Geobacter sulfurreducens by constraint-based modeling. Appl Environ Microbiol. 2006;72:1558-68.

21. Segura D, Mahadevan R, Juárez K, Lovley DR. Computational and experimental analysis of redundancy in the central metabolism of Geobacter sulfurreducens. PLoS Comput Biol. 2008;4:e36.

22. Lovley DR, Chapelle FH. Deep subsurface microbial processes. Rev Geophys. 1995;33:365-81.

23. Morita M, Malvankar NS, Franks AE, Summers ZM, Giloteaux L, Rotaru AE, et al. Potential for direct interspecies electron transfer in methanogenic wastewater digester aggregates. MBio. 2011;2: e00159-11.

24. Rotaru A-E, Shrestha PM, Liu F, Shrestha M, Shrestha D, Embree $\mathrm{M}$, et al. A new model for electron flow during anaerobic digestion: direct interspecies electron transfer to Methanosaeta for the reduction of carbon dioxide to methane. Energy Environ Sci. 2013;7:408-15.

25. Holmes DE, Shrestha PM, Walker DJF, Dang Y, Nevin KP, Woodard TL, et al. Metatranscriptomic evidence for direct interspecies electron transfer between Geobacter and Methanothrix species in methanogenic rice paddy soils. Appl Environ Microbiol. 2017;83:e00223-17.

26. Ueki T, Nevin KP, Woodard TL, Aklujkar MA, Holmes DE, Lovley DR. Construction of a Geobacter strain with exceptional growth on cathodes. Front Microbiol. 2018;9:1512.

27. Bond DR, Lovley DR. Electricity production by Geobacter sulfurreducens attached to electrodes. Appl Environ Microbiol. 2003;69:1548-55.

28. Gregory KB, Bond DR, Lovley DR. Graphite electrodes as electron donors for anaerobic respiration. Environ Microbiol. 2004;6:596-604.

29. Coppi MV, Leang C, Sandler SJ, Lovley DR. Development of a genetic system for Geobacter sulfurreducens. Appl Environ Microbiol. 2001;67:3180-7.

30. Methé BA, Nelson KE, Eisen JA, Paulsen IT, Nelson W, Heidelberg JF, et al. Genome of Geobacter sulfurreducens: metal reduction in subsurface environments. Science. 2003;302:1967-9.

31. Caccavo F, Lonergan DJ, Lovley DR, Davis M, Stolz JF, McInerney MJ. Geobacter sulfurreducens sp. nov., a hydrogen- and acetate-oxidizing dissimilatory metal-reducing microorganism. Appl Environ Microbiol. 1994;60:3752-9.

32. Caspeta L, Chen Y, Ghiaci P, Feizi A, Buskov S, Hallström BM, et al. Biofuels. Altered sterol composition renders yeast thermotolerant. Science. 2014;346:75-78.

33. Tremblay P-L, Höglund D, Koza A, Bonde I, Zhang T. Adaptation of the autotrophic acetogen Sporomusa ovata to methanol accelerates the conversion of $\mathrm{CO}_{2}$ to organic products. Sci Rep. 2015;5:16168.

34. Atsumi S, Wu T-Y, Machado IMP, Huang W-C, Chen P-Y, Pellegrini M, et al. Evolution, genomic analysis, and reconstruction of isobutanol tolerance in Escherichia coli. Mol Syst Biol. 2010;6:449. 
35. Conrad TM, Lewis NE, Palsson BØ. Microbial laboratory evolution in the era of genome-scale science. Mol Syst Biol. 2011;7:509.

36. Zhang T, Shi X-C, Xia Y, Mai L, Tremblay P-L. Escherichia coli adaptation and response to exposure to heavy atmospheric pollution. Sci Rep. 2019;9:10879.

37. Dragosits M, Mattanovich D. Adaptive laboratory evolution principles and applications for biotechnology. Micro Cell Fact. 2013;12:64.

38. Elena SF, Lenski RE. Evolution experiments with microorganisms: the dynamics and genetic bases of adaptation. Nat Rev Genet. 2003;4:457-69.

39. Wiser MJ, Ribeck N, Lenski RE. Long-term dynamics of adaptation in asexual populations. Science. 2013;342:1364-7.

40. Tremblay P-L, Summers ZM, Glaven RH, Nevin KP, Zengler K, Barrett CL, et al. A $c$-type cytochrome and a transcriptional regulator responsible for enhanced extracellular electron transfer in Geobacter sulfurreducens revealed by adaptive evolution. Environ Microbiol. 2011;13:13-23.

41. Smith JA, Tremblay P-L, Shrestha PM, Snoeyenbos-West OL, Franks AE, Nevin KP, et al. Going wireless: Fe(III) oxide reduction without pili by Geobacter sulfurreducens strain JS-1. Appl Environ Microbiol. 2014;80:4331-40.

42. Summers ZM, Ueki T, Ismail W, Haveman SA, Lovley DR. Laboratory evolution of Geobacter sulfurreducens for enhanced growth on lactate via a single-base-pair substitution in a transcriptional regulator. ISME J. 2012;6:975-83.

43. Lovley DR, Phillips EJ. Organic matter mineralization with reduction of ferric iron in anaerobic sediments. Appl Environ Microbiol. 1986;51:683-9.

44. Picard Tools - By Broad Institute. http://broadinstitute.github.io/ picard/. Accessed 29 Aug 2019.

45. Schmieder R, Edwards R. Quality control and preprocessing of metagenomic datasets. Bioinformatics. 2011;27:863-4.

46. Bushnell B, Rood J, Singer E. BBMerge - accurate paired shotgun read merging via overlap. PLoS ONE. 2017;12:e0185056.

47. Holmes DE, Nevin KP, O'Neil RA, Ward JE, Adams LA, Woodard TL, et al. Potential for quantifying expression of the Geobacteraceae citrate synthase gene to assess the activity of Geobacteraceae in the subsurface and on current-harvesting electrodes. Appl Environ Microbiol. 2005;71:6870-7.

48. Livak KJ, Schmittgen TD. Analysis of relative gene expression data using real-time quantitative PCR and the $2^{-\Delta \Delta C T}$ method. Methods. 2001;25:402-8.

49. Nevin KP, Kim B-C, Glaven RH, Johnson JP, Woodard TL, Methé BA, et al. Anode biofilm transcriptomics reveals outer surface components essential for high density current production in Geobacter sulfurreducens fuel cells. PLoS ONE. 2009;4:e5628.

50. Kovach ME, Elzer PH, Hill DS, Robertson GT, Farris MA, Roop $\mathrm{RM}$, et al. Four new derivatives of the broad-host-range cloning vector pBBR1MCS, carrying different antibiotic-resistance cassettes. Gene. 1995;166:175-6.

51. Lloyd JR, Leang C, Hodges Myerson AL, Coppi MV, Cuifo S, Methe B, et al. Biochemical and genetic characterization of PpcA, a periplasmic c-type cytochrome in Geobacter sulfurreducens. Biochem J. 2003;369:153-61.

52. Geelhoed JS, Henstra AM, Stams AJM. Carboxydotrophic growth of Geobacter sulfurreducens. Appl Microbiol Biotechnol. 2016;100:997-1007.

53. Speers AM, Reguera G. Electron donors supporting growth and electroactivity of Geobacter sulfurreducens anode biofilms. Appl Environ Microbiol. 2012;78:437-44.

54. Galushko AS, Schink B. Oxidation of acetate through reactions of the citric acid cycle by Geobacter sulfurreducens in pure culture and in syntrophic coculture. Arch Microbiol. 2000;174:314-21.
55. Coppi MV, O'Neil RA, Lovley DR. Identification of an uptake hydrogenase required for hydrogen-dependent reduction of $\mathrm{Fe}(\mathrm{III})$ and other electron acceptors by Geobacter sulfurreducens. J Bacteriol. 2004;186:3022-8.

56. Yang TH, Coppi MV, Lovley DR, Sun J. Metabolic response of Geobacter sulfurreducens towards electron donor/acceptor variation. Micro Cell Fact. 2010;9:90.

57. Coppi MV, O'neil RA, Leang C, Kaufmann F, Methé BA, Nevin $\mathrm{KP}$, et al. Involvement of Geobacter sulfurreducens SfrAB in acetate metabolism rather than intracellular, respiration-linked $\mathrm{Fe}$ (III) citrate reduction. Microbiology. 2007;153:3572-85.

58. Härle C, Kim I, Angerer A, Braun V. Signal transfer through three compartments: transcription initiation of the Escherichia coli ferric citrate transport system from the cell surface. EMBO J. 1995;14:1430-8.

59. Coppi MV. The hydrogenases of Geobacter sulfurreducens: a comparative genomic perspective. Microbiology. 2005;151:1239-54.

60. You L, Page L, Feng X, Berla B, Pakrasi HB, Tang YJ. Metabolic pathway confirmation and discovery through (13)C-labeling of proteinogenic amino acids. J Vis Exp. 2012;59:3583.

61. Butler JE, Glaven RH, Esteve-Núñez A, Núñez C, Shelobolina ES, Bond DR, et al. Genetic characterization of a single bifunctional enzyme for fumarate reduction and succinate oxidation in Geobacter sulfurreducens and engineering of fumarate reduction in Geobacter metallireducens. J Bacteriol. 2006;188:450-5.

62. Ishihama A. Functional modulation of Escherichia coli RNA polymerase. Annu Rev Microbiol. 2000;54:499-518.

63. LaCroix RA, Sandberg TE, O’Brien EJ, Utrilla J, Ebrahim A, Guzman GI, et al. Use of adaptive laboratory evolution to discover key mutations enabling rapid growth of Escherichia coli K-12 MG1655 on glucose minimal medium. Appl Environ Microbiol. 2015;81:17-30.

64. Tenaillon O, Rodríguez-Verdugo A, Gaut RL, McDonald P, Bennett AF, Long AD, et al. The molecular diversity of adaptive convergence. Science. 2012;335:457-61.

65. Rodríguez-Verdugo A, Carrillo-Cisneros D, González-González A, Gaut BS, Bennett AF. Different tradeoffs result from alternate genetic adaptations to a common environment. Proc Natl Acad Sci USA. 2014;111:12121-6.

66. Rodríguez-Verdugo A, Tenaillon O, Gaut BS. First-step mutations during adaptation restore the expression of hundreds of genes. Mol Biol Evol. 2016;33:25-39.

67. Rodríguez-Verdugo A, Gaut BS, Tenaillon O. Evolution of Escherichia coli rifampicin resistance in an antibiotic-free environment during thermal stress. BMC Evol Biol. 2013;13:50.

68. Solovyev V, Salamov A. Automatic annotation of microbial genomes and metagenomic sequences. In: Li RW, editor. Metagenomics and its applications in agriculture, biomedicine and environmental studies. Nova Science Publishers are based in Hauppauge, New York, United States; 2011. p. 61-78.

69. Cha S. [13] Succinate thiokinase from pig heart: [EC 6.2.1.4. Succinate: CoA ligase (GDP)]. Method Enzymol. 1969;13:62-69.

70. Aklujkar M, Young ND, Holmes D, Chavan M, Risso C, Kiss $\mathrm{HE}$, et al. The genome of Geobacter bemidjiensis, exemplar for the subsurface clade of Geobacter species that predominate in $\mathrm{Fe}(\mathrm{III})-$ reducing subsurface environments. BMC Genomics. 2010;11:490

71. Feist AM, Nagarajan H, Rotaru A-E, Tremblay P-L, Zhang T, Nevin KP, et al. Constraint-based modeling of carbon fixation and the energetics of electron transfer in Geobacter metallireducens. PLoS Comput Biol. 2014;10:e1003575.

72. Lovley DR. Electrically conductive pili: Biological function and potential applications in electronics. Curr Opin Electrochem. 2017;4:190-8. 